\title{
Negative feelings experienced by people with mental disorder in the workplace: A qualitative study
}

\author{
Hatsumi Yoshii \\ Faculty of Medicine, School of Health Sciences, Tohoku University, Miyagi, Japan; \\ *Corresponding Author: hatsumi@med.tohoku.ac.jp
}

Received 13 May 2013; revised 13 June 2013; accepted 15 July 2013

Copyright (C) 2013 Hatsumi Yoshii. This is an open access article distributed under the Creative Commons Attribution License, which permits unrestricted use, distribution, and reproduction in any medium, provided the original work is properly cited.

\section{ABSTRACT}

Mental disorders are a significant cause of disability and loss of workplace productivity. Many people with mental illness want to work. Occupational health in the world has to face up to psychosocial risks to protect the health of employees. My study aims are to improve negative feelings in work place and work functioning and to stimulate better coping mechanisms. Participants were collected from "Mental health daycare facility", "Regional living assistance center" and "B-type employment assistance office" in Japan. I took interviews with 25 members. The content of the interviews was categorized about negative feelings in work place. A total of 33 small category negative feelings of mental disorder were extracted and were classified into $\mathbf{1 1}$ subcategories. These subcategories were then classified into two higher-level categories: inward-directed feelings and outward-directed feelings. Inward-directed feelings include "reserve or timidity," "hesitation about being open about the illness," "anxiety about being dismissed," "regrets about resigning," "sense of isolation," "feelings of remorse," and "suffering." Outwarddirected feelings include "failure in interpersonal relationships," "distrust," "frustrations," "negative feelings toward those with mental disorder." Employment has been linked to having better social networks, to enhanced quality of life and to overall wellbeing. We will have to defend them legally. The legal and moral obligations placed on the employer require that it provides a healthy, harassment-free work environment.

Keywords: Mental Disease; Work Place; Negative
Feelings

\section{INTRODUCTION}

Among working populations in developed countries, the 1-year prevalence rate of mental health problems ranges from $10 \%$ to $18 \%$ [1]. Absenteeism due to mental health issues is increasing [2]. In addition, unemployment rates of between $75 \%$ and $89 \%$ are typically cited for people with mental illness [3]. Mental disorders are a significant cause of disability and loss of workplace productivity [4]. However, one British survey found that as many as $90 \%$ of people with mental illness wanted to return to work [5].

Interventions for mental disorders in the workplace are improving [6]. Personal and workplace partnerships are essential for supporting workers as they attempt to reach their potential and return to mainstream work [7]. For people with mental illness, employment is acknowledged to be important to their economic and social well-being, and fundamental to their mental and physical health [3]. To protect employee health now and in the future, occupational health in a changing world must address psychosocial risks [8]. For example, vulnerable youth, such as those in foster care and those with serious mental health conditions, are at increased risk of unemployment [9]. In addition, users of mental health services face difficulties in deciding whether to disclose a mental health problem to an employer [10]. Workplace stresses, e.g., lack of support by colleagues and supervisors, ergonomically poor work conditions, and excessive work load, were found to be significantly associated with a poor score on an index of work ability $(\mathrm{P}=0.001)$ [11]. Social firms and enterprises attempt to offer sustainable employment in supportive workplaces for people who are disadvantaged in the labor market [12]. Several studies have noted that individual perception of work-related barriers can strongly influence behavior, self-efficacy, and, 
ultimately, job acquisition [13].

This study aims to improve negative feelings in the workplace, improve work functioning, and stimulate better coping mechanisms. In addition, the effects of an intervention will be assessed. As part of this assessment, we will develop an action manual for assisting people with mental disorders.

\section{PARTICIPANTS AND METHODS}

\subsection{Participants}

Participants were collected from a prefecture in Japan. Their belonging was either a mental health daycare facility, regional living assistance center, or a B-type employment assistance office.

\subsection{Ethical Considerations}

Approval to conduct this research was obtained from the Graduate School of Medicine, Tohoku University and object facilities, Japan. I explained to the participants that the content of the investigation would be used for research only and that they could withdraw from the study at any time. I explained that their participation would be kept confidential and all of the data would be handled anonymously. I received informed consent forms that the participants had signed before starting in the investigation.

\subsection{Procedure}

Formal interviews were performed at each facilities, using a interview guide. It started with the general question of, "what did you experience in work place?" The questionnaire included more specific questions, such as: "Why did you do?" The duration of interviews was $1 \mathrm{~h}$ and the content was tape-recorded with permission from the participants.

\subsection{Analytical Methods}

I transcribed the content of the interviews, made wordfor-word transcripts, coded the raw data according to the context, and categorized these codes by commonality. I then extracted the subcategories of factors considered to negative feelings in work place and further categorized them to more abstract concepts. These were analytical by Atlas.ti. 7.0 (Scientific Software Development GmbH, Berlin).

\section{RESULTS}

\subsection{Participant Characteristics}

Interviews were conducted about a total 25 . The male were 16 and female were 9. Schizophrenia was most a lot of 16. High school was most a lot of 17. Unemployed was most a lot of 13 .

\subsection{Subcategories Were Further Classified into Two Groups: "Inward-Directed Feelings" and "Outward-Directed Feelings" (Table 1)}

\subsubsection{Inward-Directed Feelings}

Inward-directed feelings include "reserve or timidity", "hesitation about being open about the illness," "anxiety about being dismissed," "regrets about resigning," "sense of isolation," "feelings of remorse," and "suffering."

1) Reserve or timidity

Being unable to say anything about injustices

I am too timid to respond to senior staff, who sometimes even kick me.

I thought about filing a labor dispute appeal, but I had no physical or mental energy to lodge complaints about these injustices.

Voluntary resignation due to despair and concerns about the illness

I was afraid that the illness would recur if I continued working as a taxi driver, so I quit when I came back to work after discharge.

Hesitation to request a work hour adjustment

I feel that I can't ever talk to my employer when I can't get up in the morning. I just hesitate to do so.

Quitting due to feeling uncomfortable

I quit, because I felt uncomfortable.

Indebtedness for receiving special accommodation

I felt that I owed them for working with special accommodation.

Being unable to ask the reasons for being laid off

When I was working in a pork cutlet restaurant, out of the blue my employer told me to leave. I wanted to keep working there, but I just hesitated to ask what the reasons were. My employer was kind and friendly to me, but I simply couldn't bring myself to ask him the reasons.

I had been working there for 25 years, but I was fired for just one absence without notice. This is what I believe, although I didn't confirm it.

Having difficulties when asking for instructions

I couldn't ask my supervisor to teach me what to do, because I thought he would blame me for my incompetency.

It wasn't the atmosphere where I could ask my supervisor to teach me about the work.

I didn't ask, "Please teach me how to do this" on my own. I wasn't motivated to actively ask for instructions.

Quitting due to difficulties asking for a change in job duties

I couldn't ask my supervisor to change my duties, so I quit because of this hesitation.

Not the atmosphere to allow explanations about the 
Table 1. Negative feelings experienced by people with mental disorder in the workplace.

\begin{tabular}{|c|c|c|}
\hline Large categories & Sub-categories & Small category \\
\hline \multirow[t]{20}{*}{ Inward-directed feelings } & Reserve or timidity & Being unable to say anything about injustices \\
\hline & & Voluntary resignation due to despair and concerns about the illness \\
\hline & & Hesitation to request a work hours adjustment \\
\hline & & Quitting due to feeling uncomfortable \\
\hline & & Indebtedness for receiving special accommodation \\
\hline & & Being unable to ask the reasons for being laid off \\
\hline & & Having difficulties when asking for instructions \\
\hline & & Quitting due to difficulties asking for a change in job duties \\
\hline & & Not the atmosphere to allow explanations about the illness \\
\hline & & No requests for overtime pay \\
\hline & & Voluntary resignation out of consideration for other people \\
\hline & Hesitation to be open about the illness & Hesitation to be open about the illness \\
\hline & & Hesitation to disclose one's illness \\
\hline & Anxiety about dismissal & Anxiety about dismissal \\
\hline & & Trying to keep hospitalizations short due to anxieties about dismissal \\
\hline & Regrets about resigning & Regrets about resigning \\
\hline & & Resigning in a regretful way \\
\hline & Sense of isolation & Sense of isolation due to symptoms \\
\hline & Feelings of remorse & Blaming and spurning oneself \\
\hline & Suffering & Memories of suffering in the workplace \\
\hline \multirow[t]{12}{*}{ Outward-directed feelings } & Failure in interpersonal relationships & Failure in interpersonal relationships in the workplace \\
\hline & & Troubles at work \\
\hline & & No-one to consult \\
\hline & Distrust & Distrust about disclosure of illness \\
\hline & & Distrusting the understanding of people without mental disorder \\
\hline & & Refusing to go to work after seeing a supervisor's treatment of other staff \\
\hline & Frustration & Frustration about employment for people with mental disorder \\
\hline & & Colleagues' overreactions to symptoms \\
\hline & & Differences in the perception of disorders \\
\hline & & Different treatment by supervisor \\
\hline & $\begin{array}{c}\text { Negative feelings toward those with mental } \\
\text { disorder }\end{array}$ & Having own negative feelings toward people with mental disorder \\
\hline & & Not knowing how to deal with people with mental disorder \\
\hline
\end{tabular}

illness

My supervisor said to me, "Submit a written statement, if you have any issues." I couldn't do that because I knew rumors would then spread through the workplace.

I knew I could do it. I just needed to put five copies of the statement in an envelope and mail it. It would take a little time, but it was totally doable. Yet, I didn't feel the atmosphere was right to try.

No requests for overtime pay

I'm not that productive, because I'm a little slow, so I can't ask for overtime pay.

Voluntary resignation out of consideration for other people

When I was working in a hospital, I took a 4-hour nap while only 2 hours were allowed. So I felt I had to resign.
Someone's absence would cause trouble to everyone. People would complain to me, "You made a lot of trouble." Having thought about it, I thought it was a good time to resign.

2) Hesitation to be open about the illness

Hesitation to be open about the illness

I struggled to decide whether I should let senior staff know about my illness.

I was hesitant because it is a mental illness.

[Next time, when you have an interview for a parttime job, will you again keep your illness secret?]

I will just do the interview and not inform them. But I feel I probably should.

Hesitation to disclose one's illness

I wish I could have been open about my illness, or that 
the environment was more encouraging to be so. I was keeping my illness secret.

I didn't let my colleagues know about my clinic visits, and I took my medication secretly. But, should I have told them? I think I should have, and then I could have taken medicine in front of them and worked openly. I wish I could have taken my medicine openly, even while I was in the middle of work. I really wish that, but I didn't do it. I kept it secret, because I was scared that people might say various things to me.

Thinking back on those days, it could have been much easier if I'd asked them to understand. If I'd have done so, maybe I would have been able to continue working there.

3) Anxiety about dismissal

Anxiety about dismissal

I'm always anxious about being dismissed when the contract renewal time arrives. March is the time I felt my heart is in my mouth.

Trying to keep hospitalizations short due to anxieties about dismissal

Because longer-term hospitalizations could lead to my dismissal, I get out of the hospital within a week or less than 10 days.

4) Regrets about resigning

Regrets about resigning

I think I should have stayed there, as the company was one of the top-ranked ones. But I can't go back over the past.

I wish I hadn't quit at that time. I should have endured it.

It was wrong that I resigned from that construction company. I should have stayed in that industry.

Resigning in a regretful way

I resigned in a regretful way.

5) Sense of isolation

Sense of isolation due to symptoms

In some periods, I felt isolated, when I couldn't trust anyone, including my colleagues and parents.

6) Feelings of remorse

Blaming and spurning oneself

It may be due to my own inability that I couldn't stay in the job.

My workplace was considerate about my illness; I was given simple day-shift duties. Frankly, I was very incompetent.

I think I should take care of myself, rather than seeking help from the company. My illness is here, and it will not get better. So, I might as well do my best with the job assigned to me.

Most importantly, I couldn't make it work out. When I went there the following day, I was told to leave. I asked why, but he responded "You have left already, haven't you?" The company president told me to leave.
[How did you feel?]

I thought it might be my incompetence that was to blame.

When I was absent, I just should have called. Then, I wouldn't have been reassigned to a different job. So I really regret that now. I didn't want to go to work at that time, but I should have tried harder to go.

Looking back, I should have stayed there, even though I didn't like the job after the reshuffling.

7) Suffering

Memories of suffering in the workplace

I remember only suffering in my old job.

\subsubsection{Outward-Directed Feelings}

Outward-directed feelings include "failure in interpersonal relationships," "distrust," "frustrations," "negative feelings toward those with mental disorder."

1) Failure in interpersonal relationships

Failure in interpersonal relationships in the workplace

I am socially inept from the beginning, and I didn't want to talk to anyone at work. I didn't get into their circle.

I didn't do well with communication. I didn't do well with interpersonal relationships, either.

I am not good at communicating, and my communication skills sometimes got worse due to my illness.

I quit my 7-year job because of bad interpersonal relationships. I felt the company owner was picking on me, and the manager was mean to me, which made me feel uncomfortable. That's why I quit.

While I was working as a taxi driver, I felt I wasn't so good at socializing.

When I quit my job, my interpersonal relationships weren't going well.

I quit because I was criticized about how I managed interpersonal relationships.

I was kicked by senior staff. He kicked me, which made me disgusted with him. But I thought that fighting back wouldn't make anything better, no matter whether I won or lost. Either way would cause trouble to the company, so I might as well quit for them.

I failed in interpersonal relationships.

I had bad interpersonal relationships.

I had no communication with my colleagues, but I tried not to care about it.

Troubles at work

When I was working in a Chinese restaurant, a middle-aged female part-timer taught me how to work. But she got mad at me saying that I was slow to learn, which led to an argument between her and the supervisor. I was there watching it, and felt really depressed and sad.

No-one to consult

There were no supervisors with whom I could consult. I didn't seek anyone's help at work. 
I decided by myself whether I should quit or stay on. I didn't think about asking anyone's advice.

I never talked with anyone. I always find solutions by myself. I don't even talk with my family.

I didn't talk with anyone, I was just suffering alone.

[Did you talk with your family members when you quit your job?]

No.

[Did you consult with anyone when the restaurant owner couple said something mean to you?]

I didn't tell that to anyone.

[Did you just put up with it?]

Yes.

2) Distrust

Distrust about disclosure of illness

Because I'm scared that I might get a cold reaction if I disclose my illness, I'd rather not tell anyone.

I've talked about my illness only with friends who really understand me, so I don't talk about it easily.

I kept quiet about my illness during my job hunt, because I thought I would never get a job if I disclosed it.

If I tell my employers about my illness, I think if would affect my salary and duties. They would become anxious about assigning complex jobs to me. If something were to happen, they wouldn't want to take responsibility. I'm sure they would change my job duties.

[Why didn't you tell the shipping company about your past hospitalization and current medication?]

Well, because I thought this would prejudice them against me.

Distrusting the understanding of people without mental disorder

I don't think there is anyone who would be kind to me while I was working through a serious mental issue. Usually, people without a mental disorder wouldn't want to hire someone with one, like me.

Refusing to go to work after seeing a supervisor's treatment of other staff

Every morning I saw the deputy manager yelling at our chief, and one day all of a sudden, I found myself unable to go to work.

Being unable to consult supervisors owing to distrust

I wouldn't dare consult my employer or supervisors about my illness, because I think they would say I couldn't do the work.

\section{3) Frustration}

Frustration about employment for people with mental disorder

Because this is job is for people with mental disorder, my job doesn't have any responsibilities, which doesn't make me feel worthwhile.

Colleagues' overreactions to symptoms

No one understood about my mental illness, even when I was working in a hospital. Staff there told me,
"Why don't you take a leave of absence?" That was when I didn't have any symptoms. I was just a little emotionally sensitive, and cried once or twice. That's it. Yet they said to me, "Take a leave of absence."

Differences in the perception of disorders

When I was sick, I told my colleague. But I wasn't able to mention "schizophrenia", so I just told him I had a little depressed feeling. Depression sounds more understandable, I think.

Different treatment by supervisor

After being discharged from hospital, I returned to work. But the supervisor had changed and the new one was not so considerate of other people, which really made the workplace environment uncomfortable.

4) Negative feelings toward those with mental disorder

Having gown negative feelings toward people with mental disorder

Because I myself don't have a positive image about mental illness, I don't mention my illness to others.

It was a bad idea from the beginning that I could work in a repair shop.

People with mental disorder cannot handle that kind of complex work.

Until recently, people looked on those with mental disorder with prejudice.

Not knowing how to deal with people with mental disorder

I myself don't know how to deal with people with mental disorder. However, I do have some idea about dealing with people with intellectual or physical disorders.

\section{DISCUSSION}

Worldwide, 450 million people have a mental health problem [1]. It has been predicted that by 2020 , mental health problems and depression in particular will be the leading cause of work disability [1]. Faster production, service, and communication processes; a service and knowledge-based society; the increasing proportion of intellectual work; the growing complexity of workrelated demands; new technologies; and constant availability, mobility demands, and job insecurity all contribute to the problem of psychosocial risks in the workplace [8]. Mental health problems among workers lead to productivity losses and high costs for employers [1]. Several studies have found a relationship between common mental disorders (CMDs) and long-term sickness absence and work disability [14]. Employment has long been acknowledged as a key determinant of health [3].

This study showed "anxiety over dismissal" and "voluntary resignation due to hopelessness and concerns about illness". People with mental health problems reported being turned down for a job because of their mental health problem and stopping an employment search be- 
cause they anticipated discrimination [15]. In a study in England, one-third of people with mental health problems said that they had been dismissed or forced to resign from their jobs, $40 \%$ said that they were denied a job because of their history of psychiatric treatment, and about $60 \%$ said that they avoided applying for a job due to their expectation of unfair treatment [5].

Krupa highlighted four assumptions that underlie workplace stigma: 1) people with mental health problems lack the competence to meet the demands of work, 2) people with mental health problems are dangerous or unpredictable in the workplace, 3) working is not healthy for people with a mental health problem, and 4) providing employment to people with mental illness is an act of charity [15]. Because mental illness is difficult to understand and identify, and because it is a subjective experience, there is a greater risk of co-workers not believing the employee or being less willing to take on extra work during an employee's gradual return to work [16]. However, employment has been linked to having better social networks, to enhanced quality of life, and to overall wellbeing [3]. Work may also have a positive effect on health [17]. For a large number of people, the ability to work is an important aspect of quality of life [4]. The obligation to make "reasonable adjustments" might be necessary to bury these ditches [5]. In a word, the legal and moral obligations placed on employers require that they provide a healthy, harassment-free work environment [16]. In Australia, employers are legally obliged to support an injured worker's return to work (RTW) by obtaining relevant information about the person's capacity for work [4]. However, such protections do not exist in Japan. Thus, Japanese with mental health problems worry about disclosing their illness. Concealment and secrecy can be major stressors for stigmatized individuals [5]. My study subject experienced considerable stress due to the need for secrecy. Disclosure of a mental health problem in the workplace can also lead to discriminatory behavior from managers and colleagues, such as micro-management, lack of opportunities for advancement, over-inferring of mistakes to illness, gossip, and social exclusion [15]. Fear of discrimination, as well as legal, practical, and moral pressures, contributes to tension between disclosure and nondisclosure of a mental illness at the workplace [18]. However, perceived social support was found to mediate the association between disclosure and wellbeing [5]. We will have to defend them legally. Japan is advancing toward enacting a law that bans discrimination against handicapped people.

\section{ACKNOWLEDGEMENTS}

This work was supported by a 2013, The Uehiro Foundation on Ethics and Education, entitled "The Problem of Stigma toward People with
Mental disorder in the Workplace".

\section{REFERENCES}

[1] Hamberg-van Reenen, H.H., Proper, K.I. and van den Berg, M. (2012) Worksite mental health interventions: A systematic review of economic evaluations. Occupational \& Environmental Medicine, 69, 837-845. doi:10.1136/oemed-2012-100668

[2] Rothermund, E., Kilian, R., Hoelzer, M., Mayer, D., Mauss, D., Krueger, M., Rieger, M.A. and Guendel, H. (2012) Psychosomatic onsultation in the workplace: A new model of care at the interface of company-supported mental health care and consultation-liaison psychosomatics: Design of a mixed methods implementation study. BMC Public Health, 12, 780.

[3] Rebeiro Gruhl, K.L., Kauppi, C., Montgomery, P. and James, S. (2012) Consideration of the influence of place on access to employment for persons with serious mental illness in northeastern on tario. Rural Remote Health, 12, 2034.

[4] Reavley, N.J., Ross, A., Killackey, E.J. and Jorm, A.F. (2012) Development of guidelines to assist organisations to support employees returning to work after an episode of anxiety, depression or a related disorder: A Delphi consensus study with Australian professionals and consumers. BMC Psychiatry, 3, 12-135.

[5] Wheat, K., Brohan, E., Henderson, C. and Thornicroft, G. (2010) Mental illness and the workplace: Conceal or reveal? Journal of the Royal Society of Medicine, 103, 8386. doi:10.1258/jrsm.2009.090317

[6] Nakamura, J. (2012) Early detection and intervention for adjustment disorder and depression in the work place. Seishin Shinkeigaku Zasshi, 114, 1093-1099.

[7] Hatchard, K., Henderson, J. and Stanton, S. (2012) Workers' perspectives on self-directing mainstream return to work following acute mental illness: Reflections on partnerships. Work, 43, 43-52.

[8] Portune, R. and Arh Hig Rada Toksikol (2012) Psychosocial risks in the workplace: An increasing challenge for German and international health protection. Arhiv za higijenu rada i toksikologiju, 63, 123-131.

[9] Vorhies, V., Davis, K.E., Frounfelker, R.L. and Kaiser, S.M. (2012) Applying social and cultural capital frameworks: Understanding employment perspectives of transition age youth with serious mental health conditions. Health Services Research, 39, 257-270.

[10] Brohan, E., Henderson, C., Wheat, K., Malcolm, E., Clement, S., Barley, E.A., Slade, M. and Thornicroft, G. (2012) Systematic review of beliefs, behaviors and influencing factors associated with disclosure of a mental health problem in the workplace. BMC Psychiatry, 16, 11-12.

[11] Lazarević, S.B., Pranjić, N., Selmanović, S. and Grbović, M. (2011) Impact of work place stresses on work ability index in patients with depressive disorders. Medicinski Pregled, 64, 545-551. doi:10.2298/MPNS1112545B

[12] Williams, A., Fossey, E. and Harvey, C. (2012) Social firms: 
Sustainable employment for people with mental illness. Work, 43, 53-62.

[13] Corbiere, M., Zaniboni, S., Lecomte, T., Bond, G., Gilles, P.Y., Lesage, A. and Goldner, E. (2011) Job acquisition for people with severe mental illness enrolled in supported employment programs: A theoretically grounded empirical study. Journal of Occupational Rehabilitation, 21, 342-354. doi:10.1007/s10926-011-9315-3

[14] Arends, I., van der Klink, J.J. and Bultmann, U. (2010) Prevention of recurrent sickness absence among employees with common mental disorders: Design of a clusterrandomised controlled trial with cost-benefit and effectiveness evaluation. BMC Public Health, 15, 10-132.

[15] Brohan, E. and Thornicroft, G. (2010) Stigma and discrimination of mental health problems: Workplace implications. Occupational Medicine, 60, 414-415.

\section{doi:10.1093/occmed/kqq048}

[16] Lemieux, P., Durand, M.J. and Hong, Q.N. (2011) Supervisors' perception of the factors influencing the return to work of workers with common mental disorders. Journal of Occupational Rehabilitation, 21, 293-303. doi:10.1007/s10926-011-9316-2

[17] Brieger, P. and Hoffmann, H. (2012) How can the mentally ill achieve sustained employment? Supported employment versus pre-vocational training. Nervenarzt, 83, 840846. doi:10.1007/s00115-011-3470-9

[18] Peterson, D., Currey, N. and Collings, S. (2011) You don't look like one of them: Disclosure of mental illness in the workplace as an ongoing dilemma. Psychiatric Rehabilitation Journal, 35, 145-147. doi:10.2975/35.2.2011.145.147 